Vol. 22 N.1 de 2019 ISSN: 1516-8182

Recebimento: 05/09/2018

Aceite: 12/11/2018

DOI: $110.25059 / 2527-2594 /$ retratosdeassentamentos/2019.v22i1.342

\title{
Da luta pela terra ao reconhecimento: considerações sobre a trajetória das famílias assentadas no PDS Santa Helena e o acesso a políticas públicas
}

\author{
Bárbara El Khalil ${ }^{1}$ \\ Joelson Gonçalves de Carvalho
}

\begin{abstract}
Resumo: A expansão do capitalismo no meio rural tem como consequência histórica o conflito entre o capital e as populações camponesas. Esse conflito se materializa, não somente, mas em grande parte, na luta pela terra e na dificuldade que as populações camponesas têm em acessar políticas públicas voltadas para um desenvolvimento rural compatível com a diversidade dos sujeitos e de suas formas de organização social presentes no rural brasileiro. Neste contexto, o presente trabalho pretende analisar a conflitualidade inerente à questão agrária brasileira a partir de um estudo de caso, a saber: o Projeto de Desenvolvimento Sustentável (PDS) Santa Helena, localizado no município de São Carlos, interior do estado de São Paulo. Nosso objetivo é reconstruir a trajetória de luta pela terra dos assentados, bem como compreender como se dá o acesso da comunidade assentada a outras políticas públicas. Nossa hipótese é a de que os agricultores do Santa Helena enfrentam dificuldades para serem reconhecidos como sujeitos que podem acessar políticas públicas, o que limita, por seu turno, a capacidade de produção e reprodução social e material desses assentados.
\end{abstract}

Palavras-Chave: Questão Agrária; Assentamentos Rurais; Luta Pela Terra; Reforma Agrária; Políticas Públicas.

\begin{abstract}
The expansion of capitalism in rural brings as a historical consequence the conflict between capital and peasant populations. This conflict is materialized, not only, but in large part, by struggle for land and in difficulty that peasants have to access rural development policies compatible with the diversity of subjects and their forms of social organization presents in Brazilian rural. In this context, the present work intends to analyze the conflict inherent to the Brazilian agrarian question from a case study, namely the Sustainable Development Project (PDS) Santa Helena, located in São Carlos, an up-country city in São Paulo's state. Our objective is to reconstruct the settlers' struggle for land trajectory, as well as to understand how the settled community access other policies. Our hypothesis sustains that the farmers of Santa Helena face difficulties to be recognized as subjects that can access public policies, which limits, in turn, the production capacity and social and material reproduction of these settlers.
\end{abstract}

KEYwORDS: Agrarian Issue; Rural Settlements; Struggle for Land; Agrarian Reform; Policies.

\footnotetext{
${ }^{1}$ Mestra em Ciência Política pelo Programa de Pós-Graduação em Ciência Política (PPGPol) da Universidade Federal de São Carlos (UFSCar).E-mail: babiskhalil@hotmail.com

${ }^{2}$ Doutor em Desenvolvimento Econômico pela Universidade Estadual de Campinas (UNICAMP). Professor do Departamento de Ciências Sociais da Universidade Federal de São Carlos.E-mail: joelsonjoe@yahoo.com.br
} 


\section{INTRODUÇÃo}

As políticas públicas voltadas para desenvolvimento rural brasileiro operam uma lógica produtivista diretamente ligada aos interesses do capitalismo e, sendo assim, são parte integrante do processo de expansão do capitalismo no meio rural, trazendo consequências à toda a estrutura agrária brasileira. Essas consequências podem ser observadas ao acompanharmos as históricas transformações ocorridas no meio rural, especialmente aquelas que modificaram modos de vida e produção de determinados sujeitos sociais, notadamente os camponeses, culminando, mais recentemente, no desenvolvimento do agronegócio. Observar o desenvolvimento capitalista no campo e suas idiossincrasias é uma tarefa essencial àqueles que querem apreender a complexidade da questão agrária brasileira. Outra tarefa importante consiste em analisar as consequências geradas por tal desenvolvimento. Se, por um lado, os interesses do capital operam a maior parte das políticas de desenvolvimento, por outro, a população camponesa, marginalizada nas configurações assumidas pela estrutura agrária brasileira passa a desenvolver estratégias sociais, econômicas e políticas que tem permitido a reprodução do modo de vida camponês.

Duas estratégias adotadas pelo campesinato são: i) a luta pela terra e, a partir desta, ii) a disputa por políticas e fundos públicos. Dito isso, o presente trabalho se propõe a analisar esses dois elementos, a partir de um estudo de caso, o assentamento rural Santa Helena, localizado no município de São Carlos, em São Paulo. O objetivo é reconstruir a trajetória de luta das famílias assentadas no Sana Helena, fazendo uma análise crítica do como acontece o acesso a outras políticas públicas. Partimos da hipótese de que os agricultores do assentamento enfrentam dificuldades para serem reconhecidos como sujeitos sociais portadores de direitos e, por tanto, possíveis beneficiários de políticas públicas criadas e destinadas à população rural.

Para cumprir os objetivos propostos, organizamos o trabalho em quatro partes, para além desta introdução e das considerações finais. Na primeira parte trazemos considerações sobre questão agrária e redistribuição de terras. Em seguida, fazemos uma caracterização do assentamento foco de nosso estudo. A terceira parte traz considerações sobre a memória das famílias e a trajetória de luta dos assentados do Santa Helena, trabalhando três chaves analíticas, a saber: motivos da luta pela terra, origem e trajetória das famílias e a importância da luta pela terra. $\mathrm{Na}$ quarta parte trazemos considerações sobre a territorialização do assentamento em São Carlos e o acesso a outras políticas públicas posteriores à redistribuição de terras. Por fim, nas considerações finais, sintetizamos nossos objetivos de modo a comprovar nossas hipóteses.

\section{QUESTÃo AGRÁRIA E REDISTRIBUIÇÃo DE TERRAS}


A tese do desenvolvimento rural - e sua promoção, por meio de políticas públicas -, nos moldes capitalistas, está presente na trajetória brasileira, notadamente, pelo menos desde a primeira metade do século XX. Sabe-se, nesse ínterim, que as políticas públicas que visaram implementá-lo impactaram (e continuam impactando) diretamente a estrutura agrária do país. A esse contexto mais geral, marcado pelas idiossincrasias da penetração do capitalismo no campo, é patente a necessidade de se compreender as consequências desse tipo de desenvolvimento para as populações campesinas. À essa tentativa de compreensão do conjunto de problemas do rural brasileiro, para além do "o que se produz", avançando no "como se produz", entendendo a produção como um amálgama da organização social, política e econômica, convencionou-se chamar, em sentido lato sensu, questão agrária (CARVALHO, 2015). Neste sentido, na busca por dar densidade analítica e horizonte metodológico a este trabalho, buscaremos observá-la a partir de um processo duplo: o processo de expansão do capitalismo no campo e a conflitualidade que é dele derivada (FERNANDES, 2008).

Reiteramos que o processo de penetração do capitalismo no campo brasileiro é visível na recuperação da trajetória das políticas públicas voltadas para desenvolvimento rural. Sabemos que as décadas de 1960 e 1970 são marcadas por forte intervenção do Estado na área rural, por meio de políticas públicas voltadas ao campo que se preocuparam em alterar o padrão produtivo e tecnológico dos agricultores, a fim de incrementar e maximizar a produtividade, além da tentativa de construir dinâmicas produtivas e econômicas que relacionassem a agricultura com indústria, sob o controle desta última. Estas iniciativas fazem parte de um conjunto de projetos de desenvolvimento rural integrado, que apostaram na modernização da agricultura e na sua integração a outros setores da economia como possibilidade de superar, em tese, o dito atraso do campo. A partir dos anos $1980 \mathrm{e}$ 1990, após a redemocratização e o avanço da lógica neoliberal, as políticas públicas voltadas ao rural passaram por modificações, dentre as quais, a maior presença do capital financeiro na articulação entre produção agrícola, de um lado, e mercado consumidor, de outro (GRISA; SCHNEIDER, 2015).

Mais contemporaneamente, a partir dos anos 2000, no Brasil, os dilemas que marcam o processo de modernização da agricultura ainda estão presentes com o agronegócio ${ }^{3}$ hegemonizando, cada vez mais, a agenda e o espaço na política e na economia. De maneira dialética, é neste contexto que os sujeitos sociais que dão forma e concretude ao campesinato brasileiro, com toda a sua diversidade social, cultural e econômica, intensificam suas reivindicações por reconhecimento político

\footnotetext{
${ }^{3}$ Assim como outros autores, entendemos o agronegócio como uma associação entre o capital agroindustrial, o latifúndio exportador e o capital financeiro, sob o controle deste último. Assim, os avanços (ou não) do agronegócio ficam ao largo da melhoria das condições de vida das populações camponesas (CARVALHO, 2015, p. 137).
} 
e institucional, por meio de grupos sociais organizados que passam a demandar, além de políticas públicas, o cumprimento de direitos (GRISA; SCHNEIDER, 2015).

A expansão do capitalismo no campo, fortemente financiada pelas políticas públicas, modifica drasticamente modos de vida e engendra um processo de modernização do rural brasileiro altamente conflituoso. Essas mudanças criam, territorializam e legitimam o agronegócio, e atribuem ao campesinato uma situação de marginalidade. Nesse contexto, para que o modo de vida e a agricultura camponesa consigam se reproduzir social e materialmente, com dignidade, o campesinato, no bojo de suas estratégias de luta, passa a se opor aos avanços do capital, o que o leva a se organizar ações em diferentes esferas da vida pública brasileira (FERNANDES, 2008). Neste sentido, uma das principais ações é a luta pela terra e reforma agrária, que tem como tática principal a ocupação de terras públicas e privadas.

Fica claro, portanto, que, ocupar terras, lutar por reforma agrária e disputar fundos públicos é condição sine qua non para a existência e permanência da condição camponesa. Deste modo, a questão agrária brasileira tem como uma de suas condições estruturantes a luta entre o capital e o campesinato, que se expressa tanto pela violência que amedronta, exclui, expropria e mata, como pela dualidade incompatível entre duas lógicas distintas de desenvolvimento.

A trajetória contraditória dessa luta pode ser exemplificada pela própria Constituição Federal de 1988, que mesmo considerando o direito fundamental à propriedade privada no Brasil, instituiu que a União pode desapropriar imóveis rurais que não estejam cumprindo sua função social, e destiná-los para fins de reforma agrária. Ademais, reforça o exemplo o fato de ser da competência do Estado, garantir:

I - os instrumentos creditícios e fiscais; II - os preços compatíveis com os custos de produção e garantia de comercialização; III - o incentivo à pesquisa e à tecnologia; IV - a assistência técnica e extensão rural; V - o seguro agrícola; VI - o cooperativismo; VII - a eletrificação rural e irrigação; VIII - a habitação para o trabalhador rural (BRASIL, 1988, art. 187).

Por outro lado, também é ilustrativo as diversas reorganizações institucionais pelas quais passaram os órgãos do executivo federal direta ou indiretamente ligados à questão agrária. Focando nossa análise nas mudanças mais recentes, cabe lembrar que até maio de 2016, o Ministério de Desenvolvimento Agrário (MDA) era o responsável por implementar as políticas públicas de reforma agrária. Com a sua extinção, suas atribuições passaram a ser realizadas pela Secretaria Especial de Agricultura Familiar e do Desenvolvimento Agrário (SEAD), vinculada à Casa 
Civil. A Secretaria tinha como competências a realização da reforma agrária; a promoção do desenvolvimento sustentável da agricultura familiar; a identificação, reconhecimento, delimitação, demarcação e titulação de terras tradicionais, e a regularização fundiária da Amazônia (BRASIL, 2016). Todavia, já em 2019, as competências da SEAD são novamente transferidas, desta vez para a Secretaria de Agricultura Familiar e Cooperativismo (SAF), vinculada ao Ministério da Agricultura, Pecuária e Abastecimento (MAPA).

As recorrentes mudanças institucionais, na verdade, materializam uma certeza: as ações voltadas à reforma agrária deixaram, notadamente a partir de 2016, de serem pautadas pelo governo federal. A SAF, em sua última configuração, passou a se articular em torno de quatro eixos: assistência técnica, acesso da agricultura familiar a mercados, estruturação produtiva e crédito fundiário. A reforma agrária, objetivamente, foi substituída por uma política de crédito que, quando muito, financia a compra de terra de forma individual por cada trabalhador rural (BRASIL, 2019).

Esta situação recente de instabilidade institucional corrobora com o debate sobre a existência ou não de uma política voltada à reforma agrária no país. O fato é que, mesmo existindo instituições, e políticas nacionais voltadas à temática, podemos afirmar categoricamente que, mesmo tendo sido pauta na agenda governamental, a efetividade real dessas políticas foi nula. Um dos muitos fatores explicativos para isso é a persistência histórica de um desinteresse por parte do executivo federal em desapropriar os grandes latifúndios improdutivos para não desestabilizar os interesses do agronegócio (OLIVEIRA, 2007).

Nesse sentido, o que se convencionou chamar de reforma agrária no Brasil está muito mais ligado à uma política de criação de assentamentos rurais nos quais terras são distribuídas às famílias de camponeses, através de programas limitados e que não afetaram a estrutura fundiária brasileira, no sentido de reduzir sua desigualdade (CARVALHO, 2015). As políticas de redistribuição fundiária ficaram muito mais restritas e relacionadas à resolução de problemas localizados, notadamente focalizadas no atendimento a populações que se organizaram para pressionar o governo, do que políticas massivas, com o objetivo de impactar a concentração de terras e riquezas no campo (STÉDILE, 2012).

$\mathrm{O}$ assentamento rural Santa Helena é uma dessas inciativas. Situado no município de São Carlos, interior de São Paulo, ele - em conjunto com o assentamento rural Nova São Carlos e o acampamento Capão das Antas - materializa e dá conformidade à questão agrária na capital nacional da tecnologia ${ }^{4}$. Assim como em diversos outros assentamentos rurais no país, a trajetória de luta das famílias do Santa Helena, desde o acampamento até a redistribuição de terras e o acesso a outras políticas públicas,

\footnotetext{
${ }^{4} \mathrm{O}$ deputado Lobbe Neto apresentou um projeto de lei que conferia a São Carlos o título de Capital Nacional da Tecnologia. Em outubro de 2011 a lei foi aprovada pela presidenta Dilma Rousseff (EPTV, 2011).
} 
é marcada pelo conflito inerente à questão agrária brasileira.

\section{Caracterização do assentamento rural Santa Helena}

No final de 2005, doze famílias foram assentadas em uma área rural de São Carlos, interior de São Paulo. Nasceu assim o Plano de Desenvolvimento Sustentável Santa Helena, com uma área total de 102,5 hectares, à quatorze quilômetros do perímetro urbano do município. Atualmente, o assentamento é composto por 14 famílias que possuem lotes com cerca de 7,2 hectares cada (MENEZES; ANDRADE; CARVALHO, 2017). O assentamento é administrado pelo Instituto Nacional de Colonização e Reforma Agrária (INCRA), e por ser um PDS $^{5}$ tem uma lógica de produção diferenciada, com o intuito de que seja um território modelo para o desenvolvimento sustentável.

Em sua concepção inicial, o assentamento deveria ser capaz de se desenvolver social, cultural e territorialmente, dentro dos princípios do desenvolvimento sustentável, mas, concretamente, existem muitos desafios que dificultam a produção sob a lógica da sustentabilidade: acesso a créditos e recursos financeiros, falta de integração entre os grupos parceiros do assentamento, dificuldades na comercialização dos produtos, problemas com trâmites burocráticos, dificuldades com o abastecimento de água para as atividades agrícolas e fomento da produção, além de dificuldades com a assistência técnica (LOPES, et al, 2014).

Alguns núcleos universitários e organizações da sociedade civil possuem iniciativas de extensão em conjunto com o assentamento, pelo menos, desde 2014 (CARVALHO et al, 2014). Núcleos ligados à extensão rural universitária, economia solidária e planejamento e gestão ambiental desenvolvem projetos com as famílias assentadas. Os assentados, apoiados por esses grupos parceiros ligados à extensão rural técnica e, também, à universitária, estão tentando trabalhar as dificuldades, a fim de melhorar a qualidade de vida e a produção das famílias do Santa Helena. O trabalho tem consistido em desenvolver inciativas em conjunto com os assentados que possibilitem o acesso à recursos financeiros, principalmente através de editais de financiamento. Também em associação, ações visando melhorar a comercialização da produção assentada passaram a ser construídas. Na atualidade, as famílias assentadas no Santa Helena comercializam sua produção através de cestas de consumo, compras institucionais, além de feiras, organizadas pela prefeitura ou por grupos de economia solidária, e espaços de comercialização coletiva.

Internamente, as famílias assentadas se organizam através da Associação Santa Helena, caracterizada por disputas e dificuldades, inerentes à lógica da cooperação

${ }^{5}$ Plano de Desenvolvimento Sustentável (PDS) é um plano de assentamento diferenciado que visa o desenvolvimento de atividades ambientalmente diferenciadas com o intuito da compatibilidade entre sustentabilidade econômica e ambiental (BRASIL, 2016b). 
e do cooperativismo no meio rural. Em 2014, as dificuldades giraram em torno do cargo da presidência da associação. Já no ano seguinte, com a situação resolvida, novas eleições foram realizadas e a Associação Santa Helena não só se regularizou, como também conseguiu reviver um projeto de certificação de produtos orgânicos, através de constituição de uma Organização de Controle Social (OCS) ${ }^{6}$.

Mesmo com a presença de grupos de apoio, uma dificuldade presente no assentamento é a falta de assistência técnica e extensão rural (ATER) adequada à realidade camponesa, pois "(...) Fica patente a necessidade de assistência técnica, notadamente com o viés da agroecologica, objetivando a aplicação de novas técnicas agrícolas, de manejo e cultivo, auxílio organizacional, tanto popular quanto administrativo" (CARVALHO, et al, 2014, p. 4). Até o final de 2018, as ações de ATER, no Santa Helena, eram realizadas pelo SENAR ${ }^{7}$ e pelo SEBRAE ${ }^{8}$, intermediadas pelo Sindicato Rural Patronal de São Carlos, e pelo Instituto BioSistêmico $^{9}$ (IBS). Desde o início de 2019, as famílias deixaram de receber visitas dos técnicos do IBS e para suprir essa dificuldade adicional, o assentamento passou a ser assistido por uma cooperativa de ATER particular, por meio de um contrato privado de prestação de serviços.

Entre todos os problemas identificados, o principal está relacionado à água. São duas as fontes de captação de água do assentamento: a água destinada à produção agropecuária que é captada do lago, e a água destinada ao consumo doméstico que é captada por poço artesiano. Em 2016, por exemplo, um dos principais problemas era relativo à captação da água do lago:

Há aproximadamente dois anos atrás [2012], houve um problema mecânico na roda d'água que bombeava a água do lago para todos os lotes. Após a sua manutenção, a pressão nunca mais foi suficiente para atender todos os lotes do assentamento, sendo que desde então, a falta de água para produção tornou-se a principal dificuldade dos assentados. (LOPES, et al, 2014, p. 6)

As famílias mais próximas do lago realizavam a captação com por pequenas bombas, mas as famílias mais distantes continuavam não tendo acesso à água, e a alternativa passava a ser a implementação de reservatórios que armazenam

\footnotetext{
${ }^{6}$ Organização de Controle Social (OCS) é uma associação que permite a certificação da produção orgânica de maneira colaborativa. A garantia da qualidade orgânica é feita pelo produtor e pela sociedade conjuntamente (BRASIL, MAPA, 2016). ${ }^{7}$ O Serviço Nacional de Aprendizagem Rural (SENAR) é uma entidade paraestatal mantida pela classe patronal rural e vinculada à Confederação da Agricultura e Pecuária do Brasil (CNA), que tem como função promover cursos e capacitações para desenvolver competências profissionais e sociais em diversas profissões do meio rural (SENAR, 2016).

${ }^{8}$ O Serviço Brasileiro de Apoio às Micro e Pequenas Empresas (Sebrae) é uma entidade privada sem fins lucrativos, voltada à capacitação e promoção do desenvolvimento, criada para dar apoio a pequenos negócios de todo o país (SEBRAE, 2016). ${ }^{9}$ Empresa de assistência técnica e extensão rural, contratada pelo INCRA, para realizar que serviços de ATER no assentamento.
} 
água da chuva conhecidos como cisternas?. No início de 2019, a captação do lago foi resolvida, e o problema passou a ser o sistema de bombas do poço artesiano. As famílias por conta própria refizeram todo o sistema de encanamento que leva água até as casas, e estão aguardando que o INCRA retome as atividades, para realizar a manutenção no sistema de abastecimento do assentamento. Até nossa última visita as famílias precisavam ir até a cidade coletar água para utilizar nas atividades domésticas.

Enquanto breve caracterização, os problemas enfrentados nesse assentamento não diferem muito dos problemas de outros assentamentos. Do mesmo modo, as suas potencialidades, pois mesmo com patentes dificuldades na geração de renda, a luta pela terra e, posteriormente, a luta pela produção agrícola e reprodução social camponesa permitem que o assentamento seja, ao mesmo tempo, um território e um lócus de identidade, no qual o assentado produz, consome e vende, mas também vive, interage e se reconhece, como pode ser percebido quando observadas as trajetórias de luta desses camponeses em particular.

\section{RECUPERANDO A MEMÓRIA: TRAJETÓRIAS DE LUTA}

Lutar pela terra é um processo histórico de resistência que marcou o campesinato brasileiro em termos gerais e os assentados de reforma agrária, de maneira mais específica. Desde as resistências indígenas como a Confederação de Tamoios e a Guerra dos Potiguara, passando pelas resistências negras com os quilombos, as lutas de Canudos e Contestado, a formação das Ligas Camponesas, do MASTER, da ULTAB e da CPT, a luta pela terra está presente (MORISSAWA, 2001). Cabe registro que segundo os dados do Banco de Dados da Luta pela Terra, além do MST, o Brasil registrou em 2017 outros 136 movimentos de luta pela terra?, demonstrando a atualidade do tema e do problema (NERA, 2017).

As famílias assentadas no PDS Santa Helena têm origens diferentes: Paraná, Bahia, Minas Gerais e São Paulo, mas existe algo que está presente na trajetória de todos: a dificuldade de viver no urbano e o desejo de voltar para o campo, de conseguir um "pedaço de terra”. Esse desejo é o que mobilizou essas famílias.

A resistência do campesinato brasileiro é uma lição admirável. Em todos os períodos da história, os camponeses lutaram para entrar na terra. Lutaram contra o cativeiro, pela liberdade humana. Lutaram pela terra das mais diferentes formas, construindo organizações históricas. (FERNANDES, 2001).

A trajetória das famílias assentadas no Santa Helena faz parte desta resistência histórica. Organizadas pela FERAESP, as famílias passaram anos acampadas em 
diversos municípios do Estado de São Paulo ${ }^{10}$. Para compreender melhor a história e a luta dos agricultores, fizemos entrevistas com nove das quatorze famílias que compõem o assentamento. Essas entrevistas foram parte de um projeto de extensão realizado pelo Núcleo de Pesquisa e Extensão Rural (NuPER), intitulado "Encurtando Distâncias: a conexão da produção rural assentada ao consumo consciente em São Carlos". Este projeto teve como objetivo principal fomentar a comercialização dos produtos orgânicos do Assentamento Rural Santa Helena, por meio da produção de um material audiovisual, buscando recuperar e apresentar, aos potenciais consumidores, a trajetória de luta dessas famílias, e a importância da reforma agrária para elas.

As entrevistas nos forneceram três tipos de dados essenciais para recuperar o histórico das famílias. O primeiro conjunto de dados nos permitiu compreender porque as famílias decidiram lutar pela terra. O segundo conjunto de dados nos permitiu compreender por onde as famílias passaram antes de chegarem à ocupação que originou o PDS. O terceiro conjunto de dados coletados nos permitiu compreender a importância da reforma agrária para essas famílias.

\section{Por QUe LUTAR PEla TERRA?}

Apesar de cada família possuir sua própria trajetória, foi possível notar que a vontade de retornar às suas origens, ao campo, é algo comum a todas. Quando perguntadas sobre por que lutar pela terra, as respostas convergiram na dificuldade de viver na cidade e a esperança de conquistar um pedacinho de terra.

A entrevistada 1 aponta para uma questão central: a concentração de terras nas mãos do agronegócio:

Tantos coitados que estão debaixo da ponte, aquilo me dói o coração, tantos coitados que estão precisando de um pedaço de terra pra fazer um rancho, um barraquinho, não é? Eu vejo tanta terra aí, estragada, [nas mãos de] usinas, só cana, cana mais cana e os coitadinhos estão precisando. Sabe que isso aí [a cana] puxa mais água que eucalipto [...] A cana puxa mais água que o eucalipto, agora meu filho quantos coitadinhos que estão precisando de um pedacinho de terra pra plantar [...]. E o governo não dá. Por que saiu da terra? Porque não teve uma oportunidade uma força que nem eu tenho agora (ENTREVISTADA DA FAMÍLIA 1, 28/08/2015).

\footnotetext{
${ }^{10} \mathrm{~A}$ organização responsável pela articulação política que possibilitou a redistribuição de terra às famílias do Santa Helena foi a Federação dos Empregados Rurais Assalariados do Estado de São Paulo (FERAESP), entidade que surge na década de 1980, visando contribuir com o processo de constituição da identidade dos trabalhadores assalariados rurais enquanto classe (ALVES, 1991).
} 
Além de apontar as dificuldades da vida na cidade, principalmente relacionadas à saúde:

Mas eu vou falar uma coisa pra você, [quando] eu estava na cidade eu tinha um problema muito sério, eu tinha pressão alta, eu tinha não sei o que. Hoje eu não tenho nada. Fui fazer exame de rotina, exame de sangue, meu sangue não deu nada, graças a deus. (ENTREVISTADA DA FAMÍLIA 1, 28/08/2015)

O entrevistado 3 também apontou a dificuldade em conseguir se adaptar na cidade:

Eu vim do Paraná, fui criado na roça mesmo, na agricultura, e depois como foi ficando difícil o serviço pra lá, pouco, então eu opinei vir pra cidade. Mas não acostumei muito na cidade não e uns amigos meus [me] convidaram pra fazer a ocupação. (ENTREVISTADO DA FAMÍLIA 3, 28/08/2015)

Tanto a entrevistada 9, quanto a entrevistada 10 apontaram outro problema estruturante da questão agrária brasileira: as dificuldades encontradas pelos trabalhadores rurais - que tiveram que migrar do campo para a cidade - em conseguir garantir sua produção e reprodução social.

Nós saímos de lá da Bahia, ele é mais velho aqui do que eu. Ele veio primeiro e eu fiquei com a "molecada" lá. Eu trabalhava em casa de família, lavava, passava e ele veio trabalhar aqui em busca de uma vida melhor. [...] Lá na Bahia a gente trabalha, mas a gente ganha muito pouco. A gente sobrevive, porque em todo lugar a gente tem que lutar pra viver. Mas o ganho lá é pouco então não tinha como a gente ficar batalhando ali (ENTREVISTADA DA FAMÍLIA 8, 11/09/2015).

[...] não adianta ficar todo mundo enfiado dentro da cidade, principalmente a classe pobre, passando praticamente fome, dependente de cesta básica da prefeitura. Dependente do cartãozinho da prefeitura, [que é atribuído] quando eles querem, tem uma escolha grande ali. [...] Às vezes a maioria das pessoas que precisam não estão pegando, não estão recebendo. [...] Ficar ali todo dia na porta da assistência social pedindo um quilo de feijão, pedindo um quilo de arroz enquanto [tem] tanta terra parada que você podia estar plantando e comendo, colhendo seu próprio arroz e ainda ajudando pessoas, vendendo, doando (ENTREVISTADA DA FAMÍLIA 9, 23/09/2015). 
Para os assentados no Santa Helena a luta pela terra e a conquista de um lote foi essencial para garantir não só o pedaço de terra, mas também saúde, qualidade de vida, trabalho e renda. Para essas famílias, a luta pela terra foi o instrumento que garantiu e garante sua produção e reprodução social fora da lógica do capital, ou seja, é a garantia do modo de vida camponês.

\section{ORIGEM CAMPONESA E CONVERGÊNCIA NA LUTA}

Todos os assentados entrevistados apontam algo em comum, a origem camponesa:

[...] Filha, eu nasci na terra, meu pai tinha 15 alqueires de terra em Santa Fé do Sul. Nós ainda temos um casarão lá. [Mas como] é muito filho e ele morreu, minha mãe [também] morreu, nós tivemos que vender. Nós vendemos [e] agora estamos esperando o juiz chamar pra dividir. Aquela coisa de justiça, agora tem que esperar juiz. (ENTREVISTADA DAFAMÍLIA 1, 28/08/2015)

Aqui nós entramos há 11 anos, quer dizer, entre essa batalha toda vai pra 21 a 22 anos, então foi difícil. [Mas sempre tive] a esperança, a expectativa de um dia adquirir um lugar. Porque eu fui nascido no meio do campo, ela também, o pessoal da família dela na Bahia tinha terra, enfim, e do lado do meu pai a gente foi criado no meio da terra, no meio do sítio, tínhamos [um] sítio no município de Guanambi. Inclusive fui nascido na casa que tinha no sítio que meu pai comprou na beira do rio das Carnaíbas. (...) (ENTREVISTADO DA FAMÍLIA 2, 28/08/2015)

E é isso a trajetória, a gente já é da terra, fui nascido em sítio então a gente gosta mesmo de paixão da terra. A gente gosta de plantar, gosta de estar mexendo com a terra. Já tive várias oportunidades de serviço na cidade também, minha profissão na cidade na verdade é vigilante, mas não resisti ao convite do pessoal para poder estar fazendo a tentativa de conseguir a terra. (ENTREVISTADO DA FAMÍLIA 3, 28/08/2015)

Eu vou te falar o seguinte: quando nós entramos nessa terra eram 36 famílias. Sobraram 13, hoje são 14, [as pessoas desistiram] porque passaram uma peneira. Aqueles mais interessados, que sonhavam em ter uma terra e plantar, uma lembrança antiga dos pais que queriam [é que conseguiram]. É pouco, não é qualquer um não. (ENTREVISTADO DA FAMÍLIA 9, 23/09/2015)

Outro ponto comum sobre a trajetória das famílias é a adesão, mesmo que inconsciente, à princípios agroecológicos: 
Agente já plantava assim, a gente nunca foi de trabalhar com veneno. Aqui no meu lote vou falar pra vocês que não somos muito de ficar passando veneno nas coisas. A não ser de formiga, que não tem como. (ENTREVISTADA DA FAMÍLIA 4, 11/09/2015).

Eu fui criada num sítio no Paraná com o meu pai. Sempre a gente plantou todas as coisas sem veneno. A única coisa que meu pai passava veneno era o algodão que plantava naquela época. Que ele plantava era só. O resto, mandioca, horta, essas coisas eram todas sem veneno. Feijão, arroz, tudo sem, não tinha veneno! Então a gente nem conhecia o que era veneno. A gente já veio nesse costume (ENTREVISTADA DA FAMÍLIA 5, 11/09/2015).

Sobre a produção, os assentados também continuavam (e continuam) trabalhando na perspectiva agroecológica:

Praticamente comecei a mexer com horta agora. Antes eu plantava mais arroz, feijão, milho, não mexia com verdura. Mas eu já comecei a plantar sem o veneno, inclusive fiz o curso de produção orgânica, pra [saber] como plantar, como cuidar. Não é difícil não. Dá um pouco de trabalho. Você sabe que os produtos orgânicos dão mais trabalho que os convencionais, porque os convencionais você prepara a terra e passa o veneno, [e] o mato não sai. Então as plantas ficam no limpinho, você pode ir numa horta de planta convencional aí e você vê, está limpinha. Na produção orgânica já é diferente, você tem que plantar, meter a enxada e carpir se não... (ENTREVISTADO DA FAMÍLIA DA FAMÍLIA 5, 11/09/2015)

Em sua trajetória de luta, as 9 famílias passaram por diferentes ocupações e acampamentos. Organizamos os dados levantados no quadro abaixo, que nos mostra os municípios pelos quais passaram e, quando informado, o tempo total da jornada até serem assentados no Santa Helena: 
Quadro 1 - Municípios em que os assentados do Santa Helena participaram de ocupações

\begin{tabular}{|c|c|c|}
\hline FAMÍLIA & CIDADES & TEMPO EM OCUPAÇÕES \\
\hline 1 & Pederneiras/SP; Itapuí/SP; São Carlos/SP & Não informado \\
\hline 2 & $\begin{array}{c}\text { Alambari/SP; Itapetininga/SP; Sarapuí/SP; São } \\
\text { Carlos/SP }\end{array}$ & 11 anos \\
\hline 3 & Itapuí/SP; Barra Bonita/SP; São Carlos/SP & 2 anos \\
\hline 4 & São Simão/SP; Brotas/SP; São Carlos/SP & Não informado \\
\hline 5 & $\begin{array}{c}\text { Bauru/SP; Itapuí/SP; Boa Esperança do Sul/SP; } \\
\text { São Carlos/SP }\end{array}$ & 5 anos \\
\hline 6 & Itapuí/SP; São Carlos/SP & Não informado \\
\hline 7 & Barretos/SP; São Carlos/SP & 7 anos \\
\hline 8 & São Carlos/SP & 2 anos \\
\hline 9 & Brotas/SP; São Carlos/SP & Não informado \\
\hline
\end{tabular}

Fonte: Elaboração própria, a partir de trabalho de campo.

Entre as idas e vindas das lutas, existem alguns pontos de encontro entre as diferentes famílias que hoje compõem o Santa Helena:

Figura 1 - A convergência da trajetória de luta dos assentados rurais do Santa Helena.

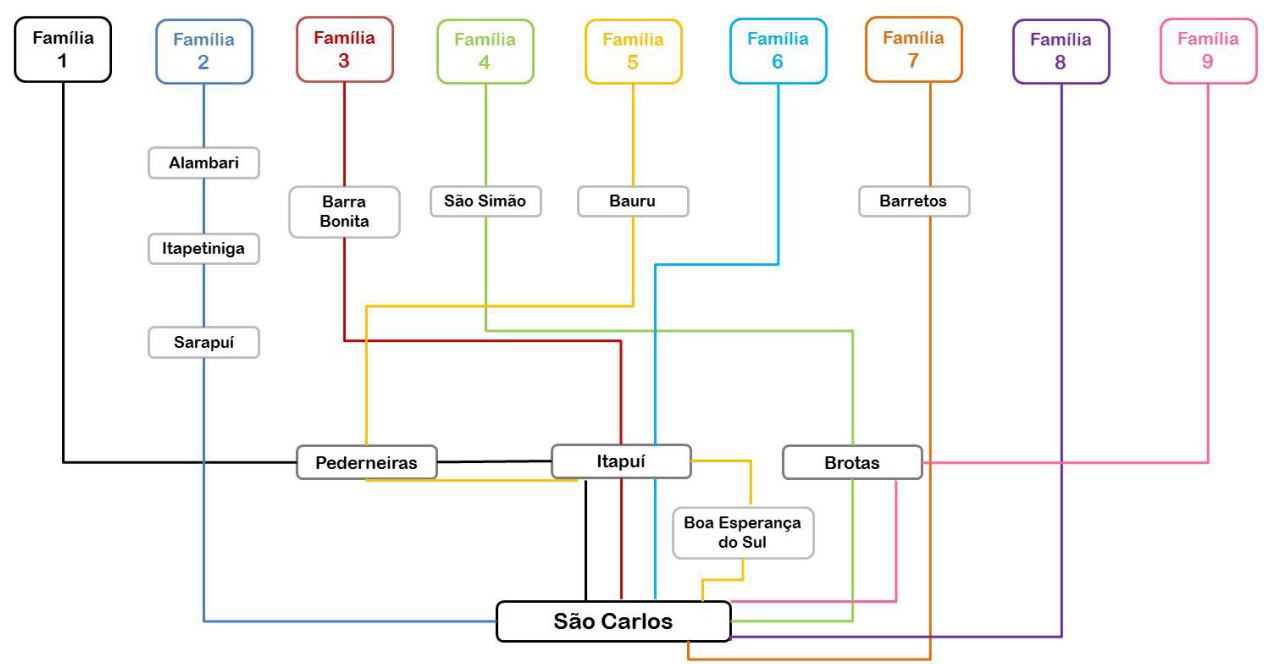

Fonte: Elaboração própria, a partir de trabalho de campo. 
É possível perceber que em determinados momentos das trajetórias essas famílias se encontraram. A figura acima nos aponta os principais pontos de convergência na luta pela terra dessas famílias, os municípios de Pederneiras, Itapuí e Brotas. Mas além da convergência entre ocupações, outro elemento fundamental é a similaridade na trajetória de vida. Na grande maioria, a origem das famílias assentadas no Santa Helena é camponesa e, mesmo que de forma involuntária, essas pessoas mobilizaram princípios agroecológicos, quando falaram sobre saúde e o uso de agrotóxicos relacionando ao passado de cada um dos entrevistados.

\section{A IMPORTÂNCIA DA LUTA PELA TERRA E POR REFORMA AGRÁRIA}

Quando perguntamos às famílias sobre a importância da reforma agrária, as respostas foram similares. Mesmo que esses relatos estejam mais relacionados às políticas de redistribuição fundiária do que a um processo de reforma agrária propriamente dito, percebemos a necessidade de sua realização. Algumas informações importantes foram coletadas.

A primeira diz respeito à necessidade de se realizar a reforma agrária para fortalecer a produção e a reprodução social camponesa:

A reforma agrária é importante porque temos muito. O nosso Brasil é rico, é poderoso, é podre de rico, só que os brasileiros aceitam tudo que vem de fora. Vamos nós para o Estados Unidos de qualquer jeito pra ver se nós entramos lá, você entendeu? Então aqui o nosso Brasil aceita tudo. Tantos coitados que estão debaixo da ponte, aquilo me dói o coração, tantos coitados que estão precisando de um pedaço de terra pra fazer um rancho, um barraquinho, não é? Eu vejo tanta terra aí, estragada, [nas mãos de] usina só cana, cana mais cana e os coitadinhos estão precisando. (ENTREVISTADA DA FAMÍLIA $1,28 / 08 / 2015)$

A reforma agrária parte mais para o campo em defesa do alimento, da comida, do arroz, do feijão, da batata, do pezinho de couve, do pezinho de banana. É a produção do campo, que é o alimento do homem, sem isso o homem não vive. Você pode estudar o que quiser, mas sempre no pratinho tem que ter a comida. Se não tiver, olha o corpo não fica de pé não, ele tomba! Então a reforma agrária, a agricultura, ela é em primeiro lugar em tudo, até nas árvores fruto do campo. (...) Eu adoro o campo. (...) Eu concordo e aprovo o campo, seja o campo cultivando pra plantar o arroz, o feijão, a melancia, o milho ou plantar as árvores frutíferas tanto pra nós como pros animaizinhos do campo. (ENTREVISTADO DA FAMÍLIA 2, 28/08/2015)

A reforma agrária, pra quem gosta da terra é importante, porque as pessoas 
que vem da lavoura tem uma certa dificuldade pra viver na cidade. [Eles] tem poucos estudos então não conseguem emprego, só conseguem se um emprego mais bruto. [Você pensa] eu vim da terra, que é mexer num serviço mais bruto, se for para ir pra cidade fazer um serviço quase igual, acaba desanimando, e você sabe que acaba indo para outro lado. Então eu acho que a reforma agrária, se fosse feita, bem-feita mesmo, resgata esse povo que vem [para a cidade]. [Por exemplo] na minha região, sitiante era bem pouco. Os grandes fazendeiros vêm apertando o pessoal e vão comprando aquelas áreas pequenas. [...] Então para eles, vende uma grande quantidade, então para eles é negócio [é fácil pois possuem muita terra], agora a gente que tinha pouca terra, a gente colhia pouco e era até difícil pra vender. [...] Do meu ponto de vista a reforma agrária é muito importante, porque o pessoal tem chance de retornar para terra e tocar a vida que gosta mesmo, mexer com a terra. (ENTREVISTADO DA FAMÍLIA 3, 28/08/2015)

É que é um processo muito doloroso o processo da reforma agrária. É assim uma coisa que só mesmo quem passou, que está nisso, entende perfeitamente o que a gente está falando. Primeiro a gente esteve numa ocupação em Brotas, o processo não deu certo, voltamos para casa e depois houve a oportunidade da gente vir aqui para o 29. [Essas terras] já eram da união, então tinha facilidade porque já estavam há muito tempo atrás destinadas para a reforma agrária. [Hoje] a maioria das pessoas já teve mais entendimento de como funciona uma reforma agrária, que não é vagabundo, que não é ladrão de terras, não é nada disso. A terra quando se destina para reforma agrária é porque já houve um processo atrás, aquela terra já foi pra união e precisa ser devolvida para os produtores plantarem. Tirar o alimento, tirar o pão de cada dia, porque não adianta ficar todo mundo enfiado dentro da cidade, principalmente a classe pobre. [...] Então você ficar ali todo dia na porta da assistência social pedindo um quilo de feijão, pedindo um quilo de arroz, enquanto [tem] tanta terra parada que você podia estar ali plantando e comendo, colhendo seu próprio arroz e ainda ajudando pessoas, vendendo, doando. (ENTREVISTADA DA FAMÍLIA 9, 23/9/2015)

A segunda diz respeito às dificuldades encontradas ao longo do processo de redistribuição das terras:

[...] a reforma agrária só tem nome. O INCRA te coloca na terra e diz se vira. Muitas vezes eles nem te dão oportunidade. Nós temos as coisas aqui porque a gente foi bem-vindo em São Carlos, pela prefeitura, pelas faculdades, principalmente a Federal, que desde o começo está aqui conosco. 
(ENTREVISTADA DA FAMÍLIA 5, 11/09/2015)

A reforma agrária eu não sei nada não viu. Eu venho lá de Barretos, agora a fazenda que eu fiquei lá tá saindo. (ENTREVISTADA DA FAMÍLIA 7, 23/09/2015)

É que a gente aqui ficou um pouco abandonado pra falar a verdade, [porque o apoio] é sempre algo mais afastado. Não era uma coisa certa, [o prefeito não falava] eu vou fazer alguma coisa para o Santa Helena. Então quando a gente entrou, e olha que estamos com 10 anos aqui, a gente praticamente não tinha nada, se precisasse fazer alguma coisa, nem um fundinho de reserva não tinha. A gente levantou tudo por a gente mesmo. Não teve o INCRA, não teve nada pra ajudar a gente. Só deram a terra e largaram nós abandonados aqui. A gente [que] chegou e já tomou dinheiro do banco, 20 mil do PRONAF. A gente aplicou em umas vacas, uns carneiros, uns porcos, fez uma casa de pinheirinho ali pra botar o paiol do gado. A gente foi fazendo, a gente está aqui porque a gente lutou e está lutando contra a gente. Porque ajuda do INCRA não teve nada, nada, nada. (ENTREVISTADO DA FAMÍLIA 8, 23/09/2015)

A percepção das famílias assentadas no Santa Helena é evidente: a reforma agrária é essencial para defender o modo de vida camponês. A cidade é, para os entrevistados, um local que remete a sofrimento e dificuldades. Que remete à perda de autonomia da própria vida e sujeição à uma lógica capitalista que não permite a garantia nem da própria subsistência. Nesse sentido, o campo é entendido como o espaço onde as famílias conseguiriam certa autonomia para garantir produção, e reprodução social e material, leia-se, sobrevivência. Mas, para que o campo se torne de fato esse espaço, as políticas públicas que atuam nele precisam ser eficientes também para a população camponesa. Os relatos sobre as dificuldades e falta de auxílio do principal órgão responsável pela reforma agrária nos indicam a distância entre o idealizado pela política e sua aplicação na prática.

\section{A territorializaÇÃo na CAPITAl da teCNOLOGia}

Apresentamos até agora um panorama que nos permite compreender como foi a trajetória da luta pela terra das famílias assentadas no Santa Helena. É necessário agora compreender como se deu o processo de territorialização dessas famílias na fazenda hoje conhecida como PDS Santa Helena, processo esse que apresenta uma característica singular: a territorialização de trabalhadores rurais em um município 
que tem uma lógica econômica ligada às atividades na área tecnológica.

O município de São Carlos, conhecido como Capital da Tecnologia, tem duas universidades públicas, a Universidade Federal de São Carlos (UFSCar) e a Universidade de São Paulo (USP). O município conta também com um polo de desenvolvimento científico e tecnológico da Empresa Brasileira de Pesquisa Agropecuária (EMBRAPA) e a Fundação ParqTec, uma organização nãogovernamental que gerencia e promove, o desenvolvimento do Polo Tecnológico de São Carlos. Essas características acabam por contribuir com a inviabilização? da questão agrária, e com os conflitos entre assentados e o agronegócio presentes no município e região.

Se, para a maioria das pessoas, São Carlos é sinônimo de fomento à tecnologia, para os assentados do Santa Helena, São Carlos é sinônimo de resistência. As famílias do assentamento encontraram muitas dificuldades ao longo do seu processo de territorialização. A principal delas foi a própria chegada à terra: mesmo com as terras confiscadas pela união, os ex-proprietários insistiam em utilizá-las.

O pessoal estava acampado numa chácara [no Condomínio 29], eles não estavam dentro daquelas terras, [pois] era pura cana aquela área. Entramos de madrugada [na fazenda], [mas] o dono, o cara que era arrendatário, o dono das canas, no outro dia umas oito da manhã já estava lá com a polícia para nos tirar. [Ele] veio, conversou com nós normalmente, [mas] tivemos que sair de vez, saímos e voltamos pra chácara. [Depois] o cara o INCRA falou assim: "essa terra aqui que é terra da união, vocês aguardem aqui na chácara que depois vocês vão e não vão sair mais". Nós ficamos na chácara mais um tempo, e quando foi dia 22 de dezembro nós entramos lá outra vez. (ENTREVISTADO DA FAMÍLIA 5, 11/09/2015)

[A fazenda] era uma terra que já era da união, então tinha a facilidade porque já estava há muito tempo atrás destinada para a reforma agrária. Só que ela estava parada, quieta, com o proprietário usufruindo, plantando [mesmo que] ela já tivesse sido confiscada há muito tempo atrás. Mas como a terra não é um automóvel, que foi confiscado e você [consegue mudar de lugar]. A terra foi confiscada, mas ela continua lá, e a justiça não está todo dia ali olhando, vigiando. Confiscou só no papel, [mas eles] eles continuavam plantando cana, arrendando e fazendo. (ENTREVISTADA DA FAMÍLIA $9,23 / 09 / 2015)$

Com o avançar das coisas, as pessoas vão tendo mais entendimento e vão 
sabendo que a nossa luta não é fácil, muitas pessoas que não estão aqui, [mas] que estiveram com nós não conseguiram passar por essa peneira que é dolorida mesmo. Lona preta, sem banheiro, vela, lamparina, tudo isso nós passamos. E polícia toda hora entrando, falando que nós tínhamos que sair, pressionando, ameaçando. Às vezes nós tínhamos medo de sair, até no bar tínhamos que ir em dois ou três porque nós corríamos riscos pelos ex-proprietários, arrendatários que entravam com a caminhonete carregada de peões armados para nos ameaçar na entrada. Enquanto isso eles falam que os marginais somos nós. As coisas [estavam] na mão da justiça, para a justiça decidir, porque é um processo demorado. A justiça pede para eles esperarem e eles não [esperavam], eles queriam fazer tudo à força bruta, toda hora entrando aqui na porta da entrada da fazenda para nos ameaçar. (ENTREVISTADA DA FAMÍLIA 9, 23/09/2015)

Outra dificuldade estava relacionada às condições de produção e reprodução social dessas famílias. Já apresentamos alguns relatos apontando obstáculos após o processo de entrada na terra. Ademais, esse quadro foi agravado pela falta de respaldo institucional por parte do INCRA, falta de acesso adequado à créditos e pouco apoio, por parte da Prefeitura Municipal, que, juntos, dificultaram ainda mais a territorialização das famílias na região. A terceira dificuldade foi relacionada à recepção que essas famílias tiveram no município. A credibilidade das famílias foi questionada constantemente por parte das elites locais, e elas tiveram dificuldades até mesmo para se relacionar com os outros moradores da área rural de São Carlos:

[Precisamos ir] acostumando as pessoas. A vizinhança foi acostumando com nós, vendo que nós não éramos saqueadores de carga, [nem] saqueadores de fazenda, [nem] saqueadores de pomar dos outros. Não era nada disso. [...] Porque um são-carlense assaltou não significa que todos os são-carlenses são assaltantes, não é verdade? Então é assim a reforma agrária. Então veja, passa lá [na televisão], quanto mais a coisa é pior, mais é mostrada. "Olha lá os sem-terra", até hoje as pessoas não falam "nós do assentamento". Elas falam os sem-terra. Só que nós não somos mais sem-terra, nós somos assentados, moradores do assentamento, e não moradores dos sem-terra. É um assentamento, um lugar que nós apropriamos, já foi documentado, registrado e tudo certinho. Nós temos CNPJ, nós temos firma aberta, temos tudo o que precisar. Temos DAP de produtor rural, temos a certificação da OCS, que é a certificação orgânica. Tá no site da receita federal, onde [você procurar] no site vai encontrar que nós somos certificados orgânicos. Não é uma coisa só nossa aqui dentro não. Nós estamos na federação como produtor 
orgânico. Aí a grande maioria [das pessoas] ainda não entendem, mas mais pra frente vão entender. (ENTREVISTADA DA FAMÍLIA 9, 23/09/2015)

Deste modo, fica patente que o processo de territorialização do PDS Santa Helena foi permeado por uma serie distinta de conflitos. Conflitos esses que estruturam as relações entre camponeses e capital. Importante deixar claro que a noção de conflitualidade extrapola o enfrentamento físico, ela é compreendida como um processo constantemente alimentado pelas contradições inerentes ao capitalismo, especialmente, com as consequentes alterações econômicas e sociais que o capitalismo traz ao campo. Nesse sentido, ela é um movimento de embate de diferentes atores sociais que participam dos processos de desenvolvimento rural (FERNANDES, 2008). A luta pela terra é uma das formas de expressão direta da conflitualidade, pois evidencia de forma nítida a desigualdade presente em processos de desenvolvimento capitalista. Mas essa conflitualidade pode se expressar em outras etapas do processo de desenvolvimento rural, em especial no acesso, por parte das populações camponesas, a políticas públicas. Se durante o processo de territorialização das famílias, as dificuldades de reconhecimento por parte da comunidade são-carlense e do próprio poder público municipal eram evidentes, mais recentemente, após 14 anos, a questão do não reconhecimento continua.

\section{O ACESSO Às POLÍtICAS PÚBLICAS}

As famílias do assentamento rural Santa Helena apresentam dificuldades constantes de escoamento de sua produção. Desde 2015, momento em que essa dificuldade é externalizada aos parceiros do assentamento, algumas iniciativas se desenvolveram para solucionar o problema: as famílias passaram a participar de feiras, as cestas de alimentos da Rede Agroecológica do Santa Helena começaram a ser entregues semanalmente para um grupo de consumidores registrados, e o assentamento pressionou o poder público municipal por sua inserção efetiva nos programas de compra pública.

As queixas sobre o acesso às políticas públicas são recorrentes no assentamento rural. Problemas com as políticas de reforma agrária, com as políticas de crédito, com as políticas de ATER e, especialmente, com as compras públicas da agricultura familiar são sempre apontados. Os próprios assentados reconhecem que essas queixas, em muitos casos, estão relacionadas aos impasses entre o assentamento e a Secretaria Municipal de Agricultura e Abastecimento (SMAA) de São Carlos. O Programa de Aquisição de Alimentos (PAA) e o Programa Nacional de Alimentação Escolar (PNAE) configuram as políticas de compras públicas da agricultura familiar, e no município são geridos pela mesma secretaria municipal, a SMAA.

Mesmo que esses programas já tenham sido implementados há algum tempo no município, desde de 2006, as famílias assentadas só começam a acessá-los em 
2016. É nesse ano que o assentamento Santa Helena passa a entregar seus produtos para o Programa de Aquisição e Alimentos. A partir de 2017, as famílias passam a participar, também, do PNAE. Das 14 famílias que compõem o assentamento, 10 delas entregam alimentos à SMAA.

Até 2016, o envolvimento do poder público municipal com as políticas de compra pública da agricultura familiar se restringiam ao diálogo com uma parcela específica dos agricultores familiares do município, aqueles que são compreendidos como "tradicionais", que adquiriram suas terras por heranças ou compra, que na maior parte das vezes são especializados, e reproduzem uma lógica produtivista extremamente agrícola e tecnicista. Para parte da população que vive nos acampamentos e assentamentos rurais de São Carlos, o diálogo com a prefeitura é, no mínimo, turbulento e, por muitas vezes, inexistente. A comunidade assentada percebe que só quando o diálogo é exercido por outros mediadores, a prefeitura acaba sendo menos resistente às suas necessidades e demandas.

O acesso ao PNAE só aconteceu em 2017, em caráter temporário, pois, segundo o poder público municipal, seria um "teste" para verificar se as famílias dariam ou não conta das demandas do programa. Desde então, o Assentamento Rural Santa Helena entrega seus produtos anualmente, tanto ao Programa de Aquisição de Alimentos, quanto ao Programa Nacional de Alimentação Escolar. Mas a relação entre a Secretaria de Agricultura e Abastecimento e as famílias assentadas se desgastou, tanto que foi preciso que um corpo técnico passasse a atuar como mediador dos conflitos, e assim surgiu, por meio de um contrato privado, a entrada de uma empresa de ATER para auxiliar os assentados, notadamente nas vendas para mercados institucionais.

O poder público municipal tende a dificultar o acesso das famílias assentadas às políticas que são formuladas, em escala federal, para a categoria camponesa. Nesse sentido, a conflitualidade está presente, não só na existência da luta pela terra no município, como também pelas dificuldades enfrentadas pelos assentados para dialogar com a SMAA. O poder público municipal dificulta o processo de implementação de políticas federais que visam amenizar as dificuldades de produção e reprodução social do campesinato.

\section{Considerações Finais}

Mesmo que o assentamento já tenha 14 anos, e que as famílias participem de diversas inciativas de comercialização diferentes, e seus representantes ocupem espaços públicos de diálogo, existe, por parte da Secretaria Municipal dificuldade de reconhecer as demandas e as próprias famílias do Santa Helena como agricultores familiares, portadores de direitos e, ao mesmo tempo, parte do público-alvo de determinadas políticas públicas. Apontamos que as principais dificuldades enfrentadas pelos assentados, na atualidade, estão relacionadas ao acesso à crédito, acesso às políticas públicas de comercialização, falta de assistência 
técnica e extensão rural adequada, e, por consequência, dificuldades em produzir e se reproduzir socialmente, dificuldades essas não restritas à esfera federal, como fizemos questão de salientar.

Para as famílias assentadas a luta pela terra é o que garantiu o lote e a condição de assentado, mas a luta também foi pela busca por melhores condições de acesso à saúde, qualidade de vida, possibilidade de trabalho e geração de renda. A luta pela terra é o que tem garantido condições mínimas de manter o modo de vida camponês por parte dos sem-terra. Mas, ao mesmo tempo, a luta pela terra é uma das formas de se evidenciar a conflitualidade da questão agrária no Brasil. As dificuldades de acesso às outras políticas públicas posteriores à redistribuição de terras, que, em tese são desenvolvidas para as populações camponesas, são outras. É justamente quando os assentados do Santa Helena tentam acessar as políticas de crédito ou de compras públicas, quando a dificuldade em ter acesso à água é constante, quando a ATER não chega de forma adequada à comunidade que podemos perceber como essas famílias não são reconhecidas como camponesas e portadoras de direitos.

Em seu processo de territorialização, o não reconhecimento esteve evidenciado: na falta de amparo institucional, especialmente por parte do INCRA; na falta de apoio da Prefeitura Municipal de São Carlos; na insistência no uso da terra pelos ex-proprietários da área, respaldados pelos próprios agentes institucionais responsáveis pela segurança pública e, até mesmo, na recepção das famílias por parte da vizinhança.

Atualmente, passados 14 anos da constituição do assentamento, algumas formas de não reconhecimento se mantêm constantes, em especial as relacionadas ao poder público municipal. A Secretaria Municipal de Agricultura e Abastecimento continua, por meio da burocratização, obstaculizando o acesso dos assentados às políticas públicas voltadas para o campesinato.

Quando os próprios assentados reconhecem a necessidade de que outros grupos e entidades intervenham no diálogo com a prefeitura municipal, podemos categoricamente apontar, por parte do poder público, um não reconhecimento dessas famílias como capazes de representar suas próprias demandas. Quando observamos a posição adotada pelo poder público municipal em relação às compras públicas, de fortalecimento daqueles agricultores familiares "tradicionais" que mais se aproximam das grandes produções convencionais, em detrimento das famílias assentadas que produzem a partir de bases agroecológicas, observamos outra forma de não reconhecimento. O poder público não reconhece as capacidades produtivas das famílias assentadas, e de forma indireta, a própria forma de produção agroecológica escolhida pelas famílias. 
Por fim, esperamos ter levantado alguns elementos que configuram a questão agrária em São Carlos, um município em que, como em tantos outros espalhados pelo Brasil, os camponeses existem e resistem às dificuldades impostas pelo capital, e pelo poder público. O estudo de caso realizado no Plano de Desenvolvimento Sustentável Santa Helena nos evidencia esse processo. Todavia, mesmo com todas as dificuldades enfrentadas, mesmo que o país não tenha passado por uma efetiva reforma agrária, mesmo com as dificuldades de acesso às políticas públicas posteriores a redistribuição de terras, as famílias do Santa Helena evidenciam motivos do porquê continuar lutando pela terra e do porquê lutar ainda mais por reforma agrária.

\section{REFERÊNCIAS}

ALMEIDA, A. H. C. Ciclos curtos de comercialização: uma revisão dos ciclos curtos de comercialização e a percepção do projeto Encurtando Distâncias através da Feira EcoSolidária da UFSCar/SP. 2015. 50 p. Monografia (Bacharelado em Ciências Sociais) - UFSCar, São Carlos, 2015.

ALVES, F. J. C. Modernização da Agricultura e Sindicalismo: as lutas dos trabalhadores assalariados rurais na região de Ribeirão Preto. 1991. 2 v. Tese (Doutorado em Economia) - UNICAMP, Campinas, 1991.

BRASIL, Governo Federal. Constituição da República Federativa do Brasil de 1988. Brasília: 1988. Disponível em: http://www.planalto.gov.br/ccivil_03/ constituicao/ConstituicaoCompilado.htm . Acessado em: 10 set. 2016.

BRASIL, Instituto Nacional de Colonização e Reforma Agrária. Criação e Modalidades de Assentamentos. Disponível em: http://www.incra.gov.br/ assentamentoscriacao . Acessado em: 10 set. 2016 b.

BRASIL, Ministério da Agricultura, Pecuária e Abastecimento. Crédito Fundiário. Disponível em: http://www.mda.gov.br/sitemda/secretaria/sra-crefun/sobre-oprograma. Acessado em: 14 mai. 2019.

BRASIL, Ministério da Agricultura. Controle Social. Disponível em: http:// www.agricultura.gov.br/portal/page/portal/Internet-MAPA/pagina-inicial/ desenvolvimento-sustentavel/organicos/regularizacao-producao-organica/controle- 
social-rpo . Acessado em: 05 set. 2016.

BRASIL, Secretaria Especial de Agricultura Familiar e do Desenvolvimento Agrário. Missão e Valores. Disponível em: http://www.mda.gov.br/sitemda/pagina/ miss\%C3\%A3o-vis\%C3\%A3o-e-valores . Acessado em: 03 set. 2016.

CARVALHO, J.G. et al. Limites, contradições e possibilidades da Extensão Rural em um PDS: o caso do assentamento Santa Helena. In: Simpósio Sobre Reforma Agrária e Questões Rurais, VI, 2014, Araraquara. Disponível em: http://www. uniara.com.br/legado/nupedor/nupedor_2014/Sessoes.html. Acessado em 03 set. 2016.

CARVALHO, J. G. Economia Agrária. 1. ed. Rio de Janeiro: Fundação Cecierj, 2015. $246 \mathrm{p}$.

DATALUTA, Banco de Dados da Luta Pela Terra. Relatório Brasil 2014. Presidente Prudente, $2015.70 \mathrm{p}$.

EPTV. Dilma aprova título de capital nacional da tecnologia a São Carlos. 2011. Investe São Paulo, São Paulo, 14, out. 2011. Disponível em: http://www.investe. sp.gov.br/noticia/dilma-aprova-titulo-de-capital-nacional-da-tecnologia-a-saocarlos/. Acessado em 03 set. 2016.

FERNANDES, B. M. Brasil: 500 anos de luta pela terra. Revista de Cultura Vozes. 9 p. mar. 2001. Disponível em: http://www.incra.gov.br/sites/default/files/uploads/ servicos/publicacoes/outras-publicacoes/brasil_500 anos_de _luta_pela_terra_pdf . Acessado em: set. 2016.

FERNANDES, B. M. Questão agrária: conflitualidade e desenvolvimento territorial. In: BUAINAIN, A. M. (ed). Luta pela terra, reforma agrária e gestão de conflitos no Brasil. 1. ed. Campinas: Editora da Unicamp, 2008. Cap. III, 173 -230.

GRISA, Catia. SCHNEIDER, Sergio. (orgs.) Políticas públicas de desenvolvimento rural no Brasil. 1. ed. Porto Alegre: Editora da UFRGS, 2015. 625 p.

LOPES, P. R. et al. Problematização participativa da realidade local do assentamento agroecológico PDS SANTA HELENA - São Carlos / SP. Cadernos de Agroecologia, v. 9, n. 4. fev. 2015. 
MENEZES, L.; ANDRADE, T. H.; CARVALHO, J. G.. Disputas entre conhecimento científico e saber local: o caso do Projeto de Desenvolvimento Sustentável (PDS) Santa Helena em São Carlos. Revista Brasileira de Gestão e Desenvolvimento Regional, v. 13, n. 1, p. 128 - 151, jan.-abr. 2017.

MORISSAWA, M. A História da Luta pela Terra e o MST. 1 ed. São Paulo: Expressão Popular, 2001. 256 p.

OLIVEIRA, A.U. Modo de Produção Capitalista, Agricultura e Reforma Agrária. 1 ed. São Paulo: Labur Edições, 2007. 185 p.

SEBRAE. O que fazemos. Disponível em: http://www.sebrae.com.br/sites/ PortalSebrae/canais adicionais/o_que fazemos . Acessado em: 05 set 2016.

SENAR. Quem Somos. Disponível em: http://www.senar.org.br/quem-somos . Acessado em: 05 set 2016.

STÉDILE, J. P. (org). A Questão Agraria no Brasil: o debate tradicional - 15001960. 1 ed. São Paulo: Expressão Popular, 2005. 304 p.

STÉDILE, J. P. Reforma Agrária. In: CALDART et al. (org). Dicionário da Educação do Campo. 1 ed. Rio de Janeiro, São Paulo: Escola Politécnica de Saúde Joaquim Venâncio, Expressão Popular, 2012. p. 659 - 668. 